\title{
Aplikasi Pengenalan Jenis Tanah Untuk Lahan Pertanian Dengan Menggunakan Metode Euclidean Distance
}

\author{
Youllia Indrawaty $\mathbf{N}^{[1]}$, Anggi Tristiyono ${ }^{[1]}$ \\ ${ }^{[1] J u r u s a n ~ T e k n i k ~ I n f o r m a t i k a, ~ F a k u l t a s ~ T e k n o l o g i ~ I n d u s t r i ~}$ \\ Institut Teknologi Nasional Bandung \\ Email:youllia@itenas.ac.id
}

\begin{abstract}
ABSTRAK
Tiap jenis tanah memiliki tekstur dan nilai manfaat yang berbeda-berbeda. Dalam melakukan identifikasi jenis tanah biasanya petugas penyuluh pertanian menggunakan cara manual dengan melakukan penelitian langsung ke lapangan dan melakukan uji laboratorium, hal ini menyebabkan kurangnya tingkat keakuratanan dan memakan banyak waktu. Berdasarkan hal tersebut maka dibutuhkan suatu teknologi image processing untuk memudahkan klasifikasi jenis tanah yang akan dimanfaatkan sebagai lahan pertanian dengan menggunakan metode Euclidean Distance. Konsep dasar metode Euclidean Distance adalah sebagai perhitungan pencocokan jarak, keputusan suatu citra tekstur tanah yang mirip adalah bila memiliki nilai paling rendah atau mendekati 0. Tekstur tanah yang telah teridentifikasi akan diproses menggunakan metode Analytical Hierarchy Process (AHP) sebagai penujang keputusan jenis tanah yang cocok digunakan untuk lahan komoditi pertanian yang tepat. Berdasarkan pengujian aplikasi, tingkat keakuratan identifikasi tekstur tanah mencapai $80 \%$ sehingga aplikasi ini dapat digunakan oleh penyuluh pertanian di Dinas Pertanian Kabupaten Muaro Jambi sebagai media penyuluhan.
\end{abstract}

Kata Kunci: Tekstur Tanah, image processing, Euclidean Distance, Analytical Hierarchy Process (AHP)

\begin{abstract}
Each type of soil has a texture and benefits of different. In identifying the type of land usually agricultural extension workers using the manual method to conduct research directly to the field and perform laboratory tests, this causes a lack of accuracylevels and takes a lot of time.. Under these conditions, it takes an image-processing technology to facilitate the classification of the type of land to be used as farmland by using Euclidean Distance. The basic concept Euclidean Distance method is a calculation of the matching distance, Decision an image similar to the texture of the soil that is if it has a minimum value or close to 0 . The texture of the soil that have been identified will be processed using the Analytical Hierarchy Process (AHP) as a decision support suitable soil types used as a commodity agricultural land right. Based on application testing, the accuracy of the identification of texture the soil reaches $80 \%$ so that these applications can be used by agricultural instructor at the department of agriculture district Muaro Jambi as media conseling.
\end{abstract}

Keywords: Soil texture, image processing, Euclidean Distance, Hierarchy Analytical Hierarchy Process (AHP) 


\section{LATAR BELAKANG}

Dinas Pertanian Kabupaten Muaro Jambi merupakan suatu instansi yang bergerak di bidang pertanian. Salah satu kerja nyatanya adalah memberikan penyuluhan pertanian kepada kelompok tani guna meningkatkan hasil pertanian dan kualitas hasil pertanian. Kualitas hasil pertanian salah satunya di tentukan dari lahan yang digunakan. Lahan pertanian berkaitan dengan tanah tempat area pertanian, dalam melakukan penyuluhan pertanian. Dalam melakukan identifikasi jenis tanah biasanya petugas penyuluh pertanian menggunakan cara manual dengan melakukan penelitian langsung ke lapangan dan melakukan uji laboratorium, hal ini menyebabkan kurangnya tingkat keakuratanan dan memakan banyak waktu.

Pada penelitian ini, dikembangkan sebuah sistem teknologi pengolahan citra digital (image processing). Dimana aplikasi ini dapat mengenali, dan memberi keputusan jenis tanah yang dideteksi, ciri dari tanah yang terdeteksi dengan metode Euclidean distance serta memberikan keputusan komoditi pertanian yang baik dengan metode pendekatan decision support system menggunakan metode AHP (Analitical Hierarcy Process). Dalam penelitian ini tekstur citra uji tanah sebagai data masukan diklasifikasikan, kemudian tekstur uji akan dibandingkan dengan tekstur citra pembanding yang ada pada basis data program. Metode euclidean distance pada dasarnya yaitu matrix yang paling sering digunakan untuk menghitung kesamaan 2 vektor. Algoritma jarak euclidean menghitung akar dari kuadrat perbedaan 2 vektor, Nilai vektor ciri suatu citra masukan yang memiliki nilai vektor ciri yang sama dengan vektor ciri citra setelah pengolahan akan memiliki nilai jarak Euclidean yang mendekati nol. Dari hasil perhitungan jarak euclidean tersebut dapat diambil keputusan suatu citra dari inputan jenis tanah adalah mirip bila memiliki jarak yang paling dekat.

Dengan memanfaatkan teknologi tersebut, maka diharapkan adanya suatu sistem pengenalan jenis tanah dan memberikan keputusan dalam menentukan komoditas pertanian yang baik. Dengan demikan kerja dari petugas penyuluh pertanian menjadi lebih ringan dalam melakukan penyuluhan kepada petani. Klasifikasi tanah yang digunakan adalah jenis tanah yang ada di area kerja Dinas Pertanian Kabupaten Muaro Jambi, yakni tanah jenis Litosol, Margel, Organosol-gambut, OrganosolHumus. Data yang dimasukkan dalam sistem ini adalah file gambar berformat Joint Photographic Group (JPG). Citra yang digunakan dalam penelitian adalah citra tekstur tanah berlapisan kedalaman $\pm 30 \mathrm{~cm}$, RGB (Red, Green, Blue). Kriteria pengambilan citra dilakukan pada intensitas cahaya 1200 lumens dengan 8 LED dan 50x-500x rasio pembesaran sesuai dengan kamera yang digunakan digital microscope endoscope USB.

\section{METODOLOGI PENELITIAN}

1. Teknik Pengumpulan Data

Data yang dibutuhkan untuk pembangunan aplikasi dilakukan dengan cara :

a. Studi literatur, dilakukan dengan mempelajari literatur terkait. Pembelajaran tersebut dilakukan dengan cara mencari referensi dan pengumpulan data yang diperoleh dari buku, jurnal, artikel.

2. Metodologi Pembangunan Sistem

Metodologi yang digunakan adalah metodologi pengembangan sistem waterfall. Adapun tahapan-tahapan dalam Waterfall sebagai berikut :

1. Analisis kebutuhan

2. Perancangan

3. Coding

4. Testing 


\section{ANALISIS DAN PEMBAHASAN}

Cara kerja dari aplikasi image processing dalam melakukan prosesIdentifikasi Tekstur Tanah dijelaskan dalamsebuah gambaran system agar memudahkan untuk mengetahui proses umum yang dilakukan aplikasi identifikasi tekstur. Gambar1 menunjukan gambaran system secara umum aplikasi tersebut.

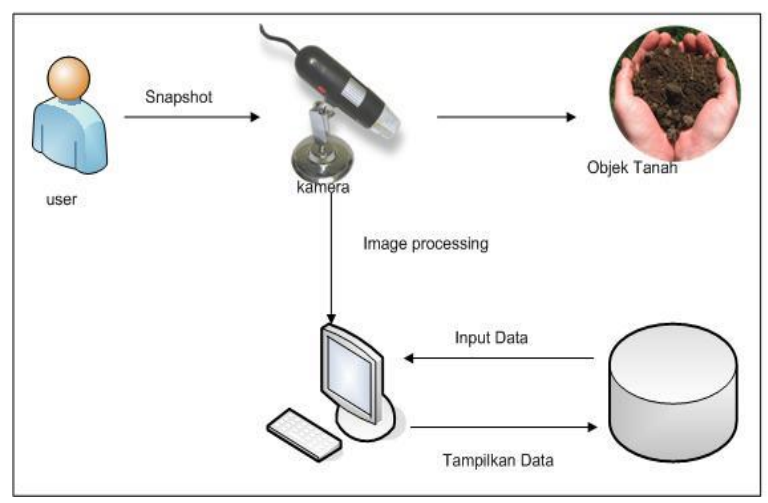

Gambar 2. Gambaran Sistem

Berikut ini adalah penjelasan dari setiap tahapan proses pada Gambar1.

1. Proses akuisisi citra di lakukan dengan menggunakan kamera Digital microscope endoscope USB UVC 2.0. Proses akuisisi citra dilakukan dengan menempatkan kamera dengan objek tanah kemudian di-snapshot. Atau dengan mengambil gambar yang telah disimpan sebelumnya.

2. Proses berikutnya adalah system merubah citra hasil snapshot menjadi grayscale, kemudian dilakukan perhitungan standar deviasi dengan perhitungan Gray Level Co-occurrence Matrices (GLCM) agar mengetahui nilai rata-rata yang telah diproses.

3. Selanjutnya membandingkan citra uji dengan citra pembanding dengan metode euclidean distance yaitu dengan cara menghitung dua matriks yang berbeda kemudian diambil nilai terkecil atau nilai yang paling mendekati 0 .

4. Setelah citra uji telah terdeteksi kemudiah cirri dari hasil pengujian citra dilakukan analisis untuk dapat menentukan komoditi pertanian yang tepat dengan metode Analytical Hierarcy Process (AHP)

5. Pada proses selanjutnya hasil dari perhitungan jarak Euclidean dan analisi Analytical Hierarcy Process (AHP) kemudian hasilnya ditampilkan pada system

\subsection{Perancangan Sistem}

Untuk proses utama sistem terdiri dari beberapa sub proses yaitu proses, grayscale image, standar deviasi, Euclidean distance dan Analytical Hierarcy Process (AHP). Untuk lebih jelasnya mengenai proses utama sistem dapat dilihat flowchart pada Gambar 3 .

\subsubsection{Snapshot}

Snapshot merpakan proses akuisisi citra. Proses pengaktifan perangkat kamera sebagai media penangkap tekstur atau objek dan pengambilan gambar yang dijadikan citra masukan yang akan diproses. Pada state ini camera device akan menampilkan hasil gambar yang di-snapshot menggunakan Kamera Digital microscope endoscope USB UVC. Dapat dilihat pada Gambar.4. 
ISSN : 2528-0015

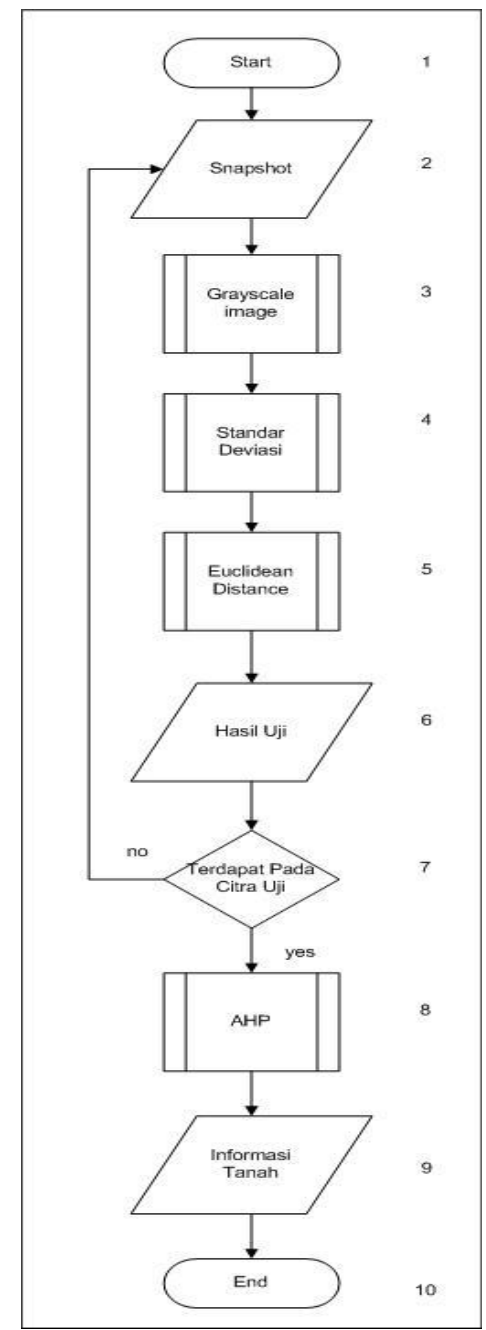

Gambar 3 Flowchart Sistem

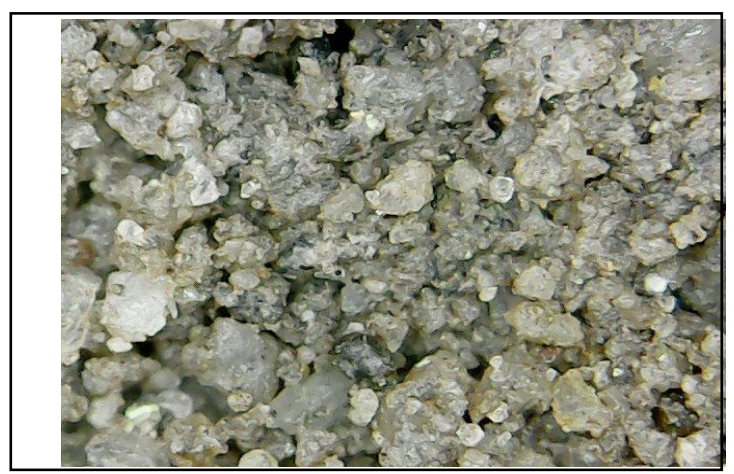

Gambar 4 Citra yang di snapshot

\subsubsection{Grayscale Image ${ }^{[4]}$}

Grayscale merupakan sebuah hasil dari proses pengolahan citra karena dapat menyederhanakan proses yang harus dilakukan dibandigkan menggunakan citra berwarna. Perhitungan secara manual konversi RGB menjadi grayscale. Misalkan sebuah citra warna berukuran $3 \times 3$ piksel dengan nilai-nilai RGB pada perhitungan matriks berikut: 


$$
\begin{aligned}
& R=\left[\begin{array}{ccc}
32 & 45 & 50 \\
66 & 78 & 80 \\
104 & 123 & 138
\end{array}\right] G=\left[\begin{array}{ccc}
31 & 41 & 52 \\
61 & 75 & 87 \\
109 & 124 & 133
\end{array}\right] \\
& B=\left[\begin{array}{ccc}
39 & 40 & 51 \\
60 & 77 & 89 \\
106 & 128 & 130
\end{array}\right]
\end{aligned}
$$

Dengan menggunakan persamaan (1) yaitu:

$$
\begin{gathered}
f o(x, y)=\frac{f i^{R}(x, y)+f i^{G}(x, y)+f i^{B}(x, y)}{3} \\
\text { Grayscale }=\left[\begin{array}{ccc}
34 & 42 & 51 \\
62 & 76 & 85 \\
106 & 125 & 133
\end{array}\right]
\end{gathered}
$$

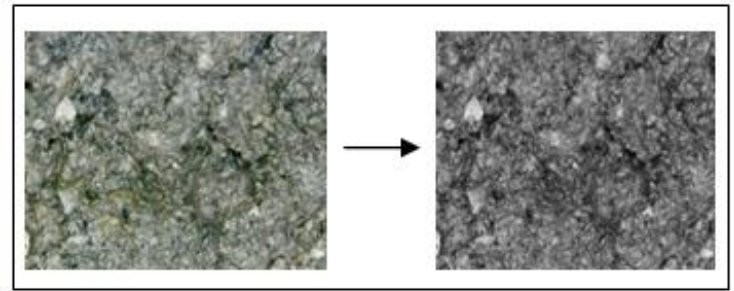

Gambar 3. Proses Grayscale

\subsubsection{Standar Deviasi ${ }^{[5]}$}

Hasil grayscale selanjutnya diproses dengan standar deviasi dengan metode Gray Level Co-occurrence Matrices (GLCM) untuk mengetahui nilai atribut yang fungsinya telah disediakan didalam pemrograman Matlab. Untuk mengetahui nilai atribut dari suatu citra maka di lakukan perhitungan manual untuk mengetahui nilai nilai entropy suatu citra. Entropy menyatakan ukuran ketidakteraturan bentuk atau pola. Nilai entropy besar memiliki tingkat keteracakan homogen (teratur) dan bernilai kecil jika struktur citra tidak teratur

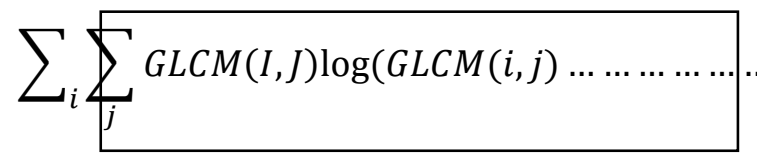

Contoh :

Berdasarkan hasil nilai matriks grayscale sebelumnya, misalkan untuk menghitung piksel $(3,2)$, maka :

$$
\begin{gathered}
(3,2)=a=3 \\
b=2 \\
(3-2)^{2} \times \log 1
\end{gathered}
$$

\subsubsection{Euclidean Distance ${ }^{[6]}$}

Tahapan selanjutnya dalam identifikasi tekstur tanah selanjutnya adalah perhitungan nilai Euclidean Distance untuk menghitung nilai kemiripan citra uji dan citra pembanding. Model matematis Euclidean distance dapat di ekspresikan menggunakan persamaan :

$$
\mathrm{D}(A, B)=\sqrt{\sum_{i=1}^{n}(A i-B i)^{2}}
$$

Berikut ini adalah contoh perhitungan nilai Euclidean distance : 
Terdapat dua buah vektor image dengan nilai

$$
\begin{aligned}
& A=[0,3,4,5] \\
& B=[7,6,3,-1]
\end{aligned}
$$

Maka Euclidean distance dari dua vektor image adalah:

$$
\begin{aligned}
& \|A\|=\left[\sum_{i} A_{i}^{2}\right]^{1 / 2}=\sqrt{0^{2}+3^{2}+4^{2}+5^{2}}=\sqrt{50} \\
& \|B\|=\left[\sum_{i} B_{i}^{2}\right]^{1 / 2}=\sqrt{7^{2}+6^{2}+3^{2}+(-1)^{2}}=\sqrt{95} \\
& \bar{A}=\left[\frac{0}{\sqrt{50}}, \frac{3}{\sqrt{50}}, \frac{4}{\sqrt{50}}, \frac{5}{\sqrt{50}}\right]=[0,0.42,0.56,0.7] \\
& \bar{B}=\left[\frac{7}{\sqrt{95}}, \frac{6}{\sqrt{95}}, \frac{3}{\sqrt{95}}, \frac{-1}{\sqrt{95}}\right]=[0.72,0.61,0.3,-0.1] \\
& \bar{d}(A, B)=\sqrt{(0-0.72)^{2}+(0.42-0.61)^{2}+(0.56-0.3)^{2}+(0.7+0.1)^{2}} \\
& \bar{d}(A, B)=\sqrt{1.25} \\
& \bar{d}(A, B)=1.11
\end{aligned}
$$

\subsubsection{Analitycal Hierarcy Process ${ }^{[7]}$}

Tahap akhir dari proses pengenalan jenis tanah adalah menentukan komoditi pertanian berdasarkan citra uji yang telah diketahui dengan metode Analytical Hierarcy Process (AHP).

Berikut adalah penjelasan dari masing-masing prosedur dari AHP:

1. Dekomposisis masalah/menyusun hirarki. Dekomposisi masalah adalah langkah dimana suatu tujuan (Goal) yang telah ditetapkan selanjutnya diuraikan secara sistematis kedalam struktur hirarki hingga tujuan dapat dicapai secara rasional.

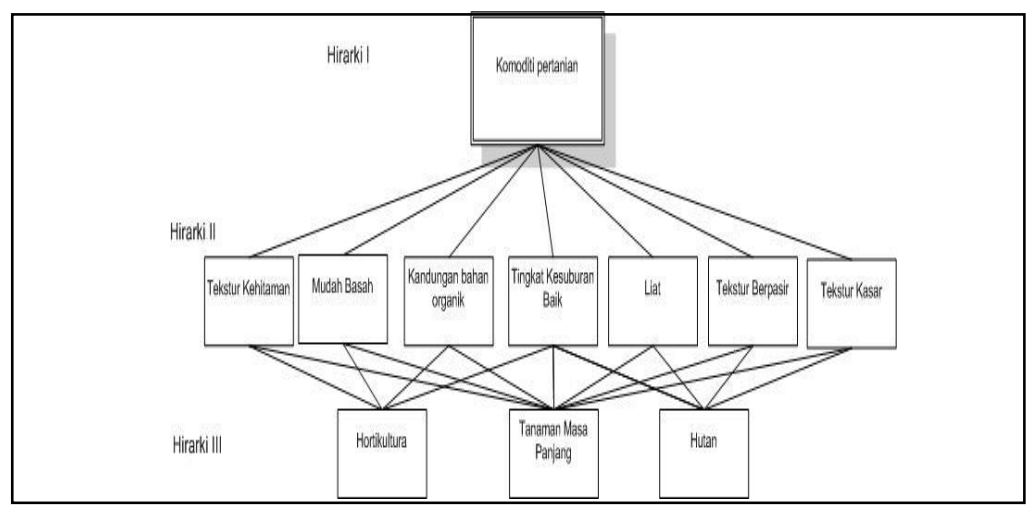

Gambar 9. Proses Hirarki AHP

2. Penilaian/pembobotan untuk membandingkan elemen-elemen

3. Penyusunan matriks dan uji konsistensi

a. Menyatukan pendapat dari beberapa kuisioner

b. Menyusun matriks perbandingan

c. Uji konsistensi

d. Menentukan nilai indeks konsistensi

4. Penetapan prioritas pada masing-masing hirarki

5. Pnarikan kesimpulan. 


\subsection{Pengujian Sistem}

Pengujian sistem dilakukan dengan mengakuisisi citra tekstur tanah yang kemudian akan dijadikan citra uji untuk dihitung jarak terdekatnya dengan citra pembanding yang sudah ada didalam database aplikasi. Hasil dari perhitungan citra uji yang telah terdeteksi kemudian akan dijadikan bahan acuan sebagai analisa komoditi pertanian sesuai dengan ciri umum yang telah ditentukan.

\subsubsection{Tahap Akuisisi Citra}

Pada proses akuisisi citra, citra uji yang masuk akan melalui proses awal yang memproses citra RGB menjadi Grayscale.

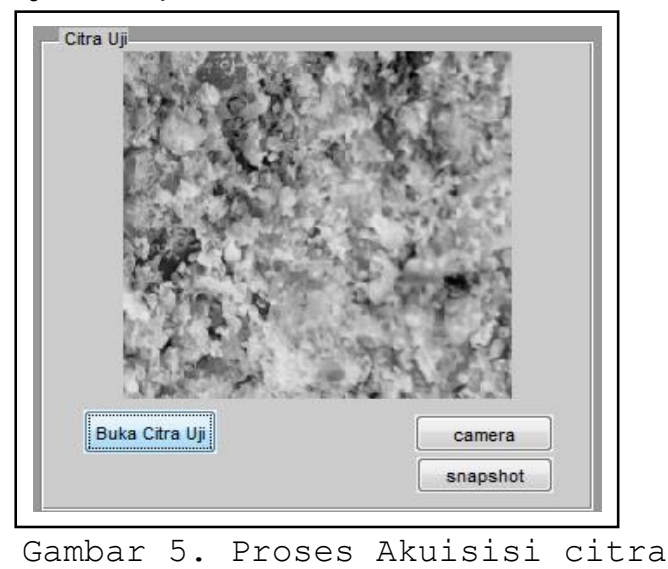

\subsubsection{Perhitungan Jarak Euclidean}

Hasil implementasi dari menghitung jarak Euclidean untuk mengetahu kemiripan citra uji dengan citra pembanding yang ditentukan oleh nilai Euclidean yang terendah atau mendekati 0 .

Hasil perhitungan nilai Euclidean yang didapat akan langsung diproses untuk menampilkan ciri tanah secara umum yang nantinya menjadi bahan acuan pengambilan keputusan komoditas pertanian.

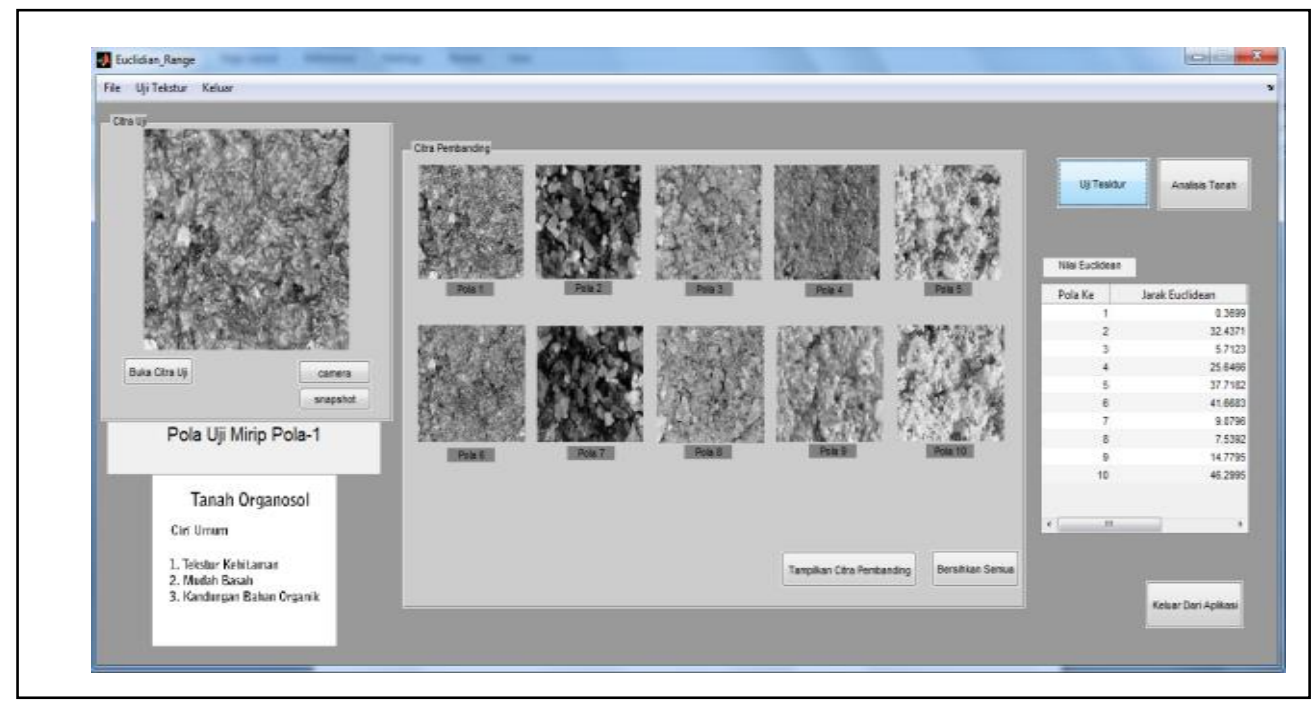

Gambar 6. Perhitungan Jarak Euclidean 
Tabel 1. Tabel Pengujian system

\begin{tabular}{|c|c|c|c|c|}
\hline $\begin{array}{c}\text { Tanah Yang } \\
\text { Diuji }\end{array}$ & $\begin{array}{l}\text { Output } \\
\text { Aplikasi }\end{array}$ & Nama Jenis Tanah & $\begin{array}{c}\text { Nilai } \\
\text { euclidean }\end{array}$ & Kesimpulan \\
\hline \multirow{10}{*}{$\begin{array}{c}\text { Tanah } 1 \\
\text { (Organosol) }\end{array}$} & Pola 1 & Organosol & 0.3699 & Match \\
\hline & Pola 2 & Litosol & 9.0874 & \\
\hline & Pola 3 & Organosol Humus & 5.7123 & \\
\hline & Pola 4 & Organosol Gambut & 25.6466 & \\
\hline & Pola 5 & Mergel & 37.7182 & \\
\hline & Pola 6 & Organosol & 9.2559 & \\
\hline & Pola 7 & Litosol & 41.6683 & \\
\hline & Pola 8 & Organosol Humus & 7.5392 & \\
\hline & Pola 9 & Organosol Gambut & 14.7795 & \\
\hline & Pola 10 & Mergel & 56.2995 & \\
\hline \multirow{10}{*}{$\begin{array}{c}\text { Tanah } 2 \\
\text { (Organosol } \\
\text { Humus) }\end{array}$} & Pola 1 & Organosol & 9.3061 & \\
\hline & Pola 2 & Litosol & 18.0236 & \\
\hline & Pola 3 & Organosol Humus & 3.2239 & \\
\hline & Pola 4 & Organosol Gambut & 34.5828 & \\
\hline & Pola 5 & Mergel & 28.7821 & \\
\hline & Pola 6 & Organosol & 18.1921 & \\
\hline & Pola 7 & Litosol & 50.6045 & \\
\hline & Pola 8 & Organosol Humus & 1.3969 & Match \\
\hline & Pola 9 & Organosol Gambut & 5.8433 & \\
\hline & Pola 10 & Mergel & 37.3633 & \\
\hline \multirow{10}{*}{$\begin{array}{c}\text { Tanah } 3 \\
\text { (Organosol } \\
\text { Gambut) }\end{array}$} & Pola 1 & Organosol & 24.5134 & \\
\hline & Pola 2 & Litosol & 15.7960 & \\
\hline & Pola 3 & Organosol Humus & 30.5957 & \\
\hline & Pola 4 & Organosol Gambut & 0.7632 & Match \\
\hline & Pola 5 & Mergel & 62.6016 & \\
\hline & Pola 6 & Organosol & 15.6275 & \\
\hline & Pola 7 & Litosol & 16.7849 & \\
\hline & Pola 8 & Organosol Humus & 32.4226 & \\
\hline & Pola 9 & Organosol Gambut & 39.6629 & \\
\hline & Pola 10 & Mergel & 71.1829 & \\
\hline \multirow{10}{*}{$\begin{array}{l}\text { Tanah } 4 \\
\text { (Mergel) }\end{array}$} & Pola 1 & Organosol & 43.3178 & \\
\hline & Pola 2 & Litosol & 52.0352 & \\
\hline & Pola 3 & Organosol Humus & 37.2355 & \\
\hline & Pola 4 & Organosol Gambut & 68.5944 & \\
\hline & Pola 5 & Mergel & 5.2296 & \\
\hline & Pola 6 & Organosol & 52.2037 & \\
\hline & Pola 7 & Litosol & 84.6161 & \\
\hline & Pola 8 & Organosol Humus & 35.4086 & \\
\hline & Pola 9 & Organosol Gambut & 28.1684 & \\
\hline & Pola 10 & Mergel & 3.3516 & Match \\
\hline \multirow{10}{*}{$\begin{array}{l}\text { Tanah } 5 \\
\text { (Litosol) }\end{array}$} & Pola 1 & Organosol & 23.1892 & \\
\hline & Pola 2 & Litosol & 14.4718 & \\
\hline & Pola 3 & Organosol Humus & 29.2715 & \\
\hline & Pola 4 & Organosol Gambut & 2.0874 & No Match \\
\hline & Pola 5 & Mergel & 61.2774 & \\
\hline & Pola 6 & Organosol & 14.3033 & \\
\hline & Pola 7 & Litosol & 18.1091 & \\
\hline & Pola 8 & Organosol Humus & 31.0984 & \\
\hline & Pola 9 & Organosol Gambut & 38.3387 & \\
\hline & Pola 10 & Mergel & 69.8587 & \\
\hline
\end{tabular}


Berdasarkan Tabel 1 proses pengujian system dalam mendeteksi tekstur tanah, dalam hal ini Tanah 1 sampai tanah 5 dilakukan pencocokan dengan sepuluh pola citra pembanding yang ada pada database aplikasi. Nilai jarak Euclidean dihitung dari hasil perbandigan citra uji dengan citra pembanding. Citra uji yang dinyatakan match adalah citra yang perhitungan nilai jarak euclidian nya paling kecil atau mendekati 0 . Pada Tanah 1 dengan jenis tanah Organosol memiliki nilai terendah dibandingkan dengan nilai pola lainnya, dengan demikian Tanah 1 dengan jenis tanah Organosol paling mirip dengan Pola 1 yang berjenis Organosol.

Pada beberapa kali pengujian yang di lakukan, sistem belum mampu menghasilkan kecocokan data antara citra uji dan citra pembanding. Hal ini disebabkan karena citra yang diakuisisi berupa tekstur tanah yang teksturnya terdapat banyak kemiripan. Hal ini menyebabkan rentang nilai yang dihasilkan pada tahap ekstraksi ciri terlalu kecil, sehingga menyebabkan ketidak konsistenan system dalam menentukan kesesuaian/kecocokan data antara citra uji dan citra pembanding .

Beberapa Faktor yang dapat mempengaruhi keberhasilan system dalam mengenali Tekstur Tanah :

1. Resolusi kamera dan system pencahayaan dapat menghasilkan nilai yang berbeda. Semakin tinggi resolusi kamera yang digunakan maka semakin baik akurasi nilai yang didapat

2. Tekstur tanah yang perbedaannya hampir sama. Tanah yang berjenis sama namun kelembaban berbeda akan menyebabkan perubahan tekstur asli tanah. Hal ini menyebabkan nilai citra akan berubah.

\subsubsection{Pengujian Analisis Pemanfaatan Sesuai Jenis Tanah}

Analisis pemanfaatan komoditi pertanian sesuai ciri umum yang telah ditentukan sesuai hasil yang diperoleh dari perhitungan jarak Euclidean

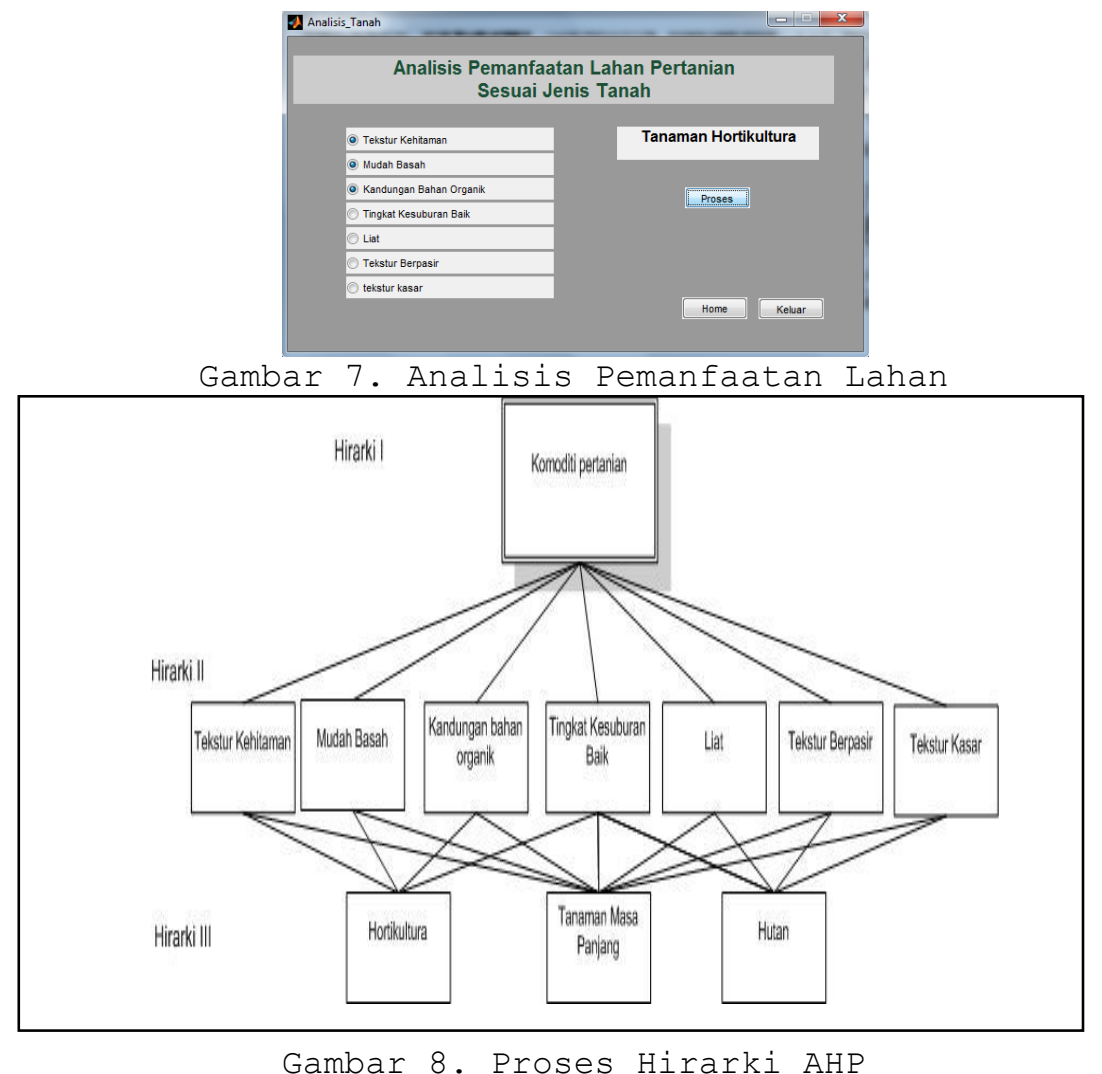


Analisis pemanfaatan Lahan pertanian sesuai jenis tanah merupakan proses Analycal Hierarcy Proces yang data penunjangnya didapat dari hasil wawancara seorang ahli dalam hal ini adalah seorang Penyuluh Pertanian lapangan.

\section{KESIMPULAN}

Kesimpulan dari hasil analisis dan perancangan aplikasi pengenalan jenis tanah untuk lahan pertanian dengan metode Euclidean distance dan sistim pengambilan keputusan menggunakan Analycal Hierarcy Proces (AHP). Diambil beberapa kesimpulan berdasarkan implementasi dan pengujian sistem yang telah dilakukan.

1. Berdasarkan Tabel 1. Metode perhitungan jarak Euclidean dari sistem yang dibangun dapat mencapai ke akuratan hingga $80 \%$ dari 5 sampel citra uji.

2. Nilai citra dapat berubah-ubah disebabkan tekstur tanah yang perbedaannya hampir sama. Tanah yang berjenis sama namun kelembaban berbeda akan menyebabkan perubahan tekstur asli tanah. Hal ini menyebabkan nilai citra akan berubah.

\section{DAFTAR RUJUKAN}

[1]Abdul Kadir dan Adhi Susanto. 2013. Teori dan Aplikasi Pengolahan Citra. Yogyakarta.

[2]Resti Wulanningrum , 2012, "Pengenalan Rumput Laut Menggunakan Euclidean Distance Berbasis Ekstraksi Fitur"

[3] Nawardisyana. Pengantar Penggunaan AHP (Analytical Hierarcy Process). http://mawardisyana.blogspot.com/2013/04/pengantar-penggunaan-ahpanalytical.html, di akses online pada Maret 2015
[4]Wikipedia
Editor.
2013.
Euclidean
Distance.

http://en.wikipedia.org/wiki/Euclidean_distance, diakses online tanggal 5 Maret 2015. 